Bangladesh J. Bot. 48(4): 973-979, 2019 (December)

\title{
EFFECTS OF ENVIRONMENTAL FACTORS ON POPULATION DYNAMICS OF RICE EARHEAD BUG AND THEIR MANAGEMENT WITH NEWER INSECTICIDE COMBINATIONS AND SOLE INSECTICIDE
}

\author{
Kamal Ravi Sharma*, SVS Raju, KN Singh ${ }^{1}$ and D Rakshith Roshan \\ Department of Entomology and Agril. Zoology, Banaras Hindu University, \\ Varanasi-221 005, India
}

Keywords: Rice, Earhead bug, Population dynamics, Environmental factors, Insecticides

\begin{abstract}
An experiment was conducted to study the population dynamics of rice earhead bug and to evaluate the efficacy of newer insecticide combinations and sole insecticide along with untreated control. The rice earhead bug population was first recorded on 36th standard week as 1 nos./10 sweep nets and peak population (17 nos./10 sweep nets) was observed during 44th standard week. The correlation analysis revealed that rice earhead bug showed significant negative correlation with rainfall while the remaining weather parameters like average relative humidity and average temperature were found negative and non-significantly correlated. The overall data of efficacy revealed that all insecticidal treatments were significantly superior over untreated control. However, the plots treated with fipronil 5\% + buprofezin $20 \%$ SC recorded the lowest number of rice earhead bug population (2.10 and 3.51 nos./5 sweep nets) after first and second insecticidal sprays, respectively, followed by indoxacarb $10 \%$ + thiamethoxam $10 \%$ WG (2.47 and 4.25 nos./5 sweep nets, respectively). Whereas, application of thiamethoxam 25\% WG and buprofezin 25\% singly SC were recorded as third and fourth best treatments, respectively.
\end{abstract}

\section{Introduction}

Rice (Oryza sativa L.) is the most important food crop in the developing world and is the staple food over half the world's population. Almost $90 \%$ of rice is produced and consumed in Asian countries like China, India, Japan, Korea Republic, Srilanka, Pakistan, Bangladesh, etc., (Nadaf et al. 2016). India is one of the major rice growing countries and it leads the world in rice area with 43.38 million hectares with a production of 104.32 million tonnes (Anon. 2017). Rice crop subjected to attack about 128 species of insects have been reported to ravage the rice field and out of this only 15 to 20 insects are regarded as economically obnoxious species (Kalode 2005).

Among these major insect pests, rice earhead bug, Leptocorsia acuta (Thunberg) also known as "gundhi bug" is one of the serious sap sucking pests of paddy (Hashmi et al. 1983). Both the nymphs and adults suck the sap from developing grains during milking growth stage and thus make them fragmentary or entirely chaffy. Panicle is completely shattered and becomes white coloured under grievous infestation at growing stage (Israel and Rao 1961). Rice earhead bug induced yield loss may range from 25 - 35\% (Banerjee and Chatterjee 1982) and in the eastern part of country like Uttar Pradesh and Bihar, it has been reported that up to $70 \%$ damage of the crop to be extended (Verma et al. 1979). The environmental factors like relative humidity, temperature, rainfall etc., have direct effect on insect pest population development and their reproduction. Rainfall is not only important for survival, but also for disposal of insect population (Sharma et al. 2018). Among the various methods, application of insecticides is one of the most

*Author for correspondence: <kamalr.sharma4@bhu.ac.in>. 'Gharda Chemicals Ltd., Thane, Maharashtra, India. 
effective methods of pests control and it yields quick results, supporting its application in integrated pest management strategies. However, the persistent use of the same insecticides or group of insecticide having same mode of action will become less effective against insects because of developing possible resistance. Keeping in view of the above, the present study was undertaken to evaluate the effect of environmental factors and efficacy of certain newer insecticide combinations with different novel mode of action and their respective sole insecticide formulations against rice earhead bug on rice.

\section{Materials and Methods}

Field experiments were conducted during the Kharif season of 2016 at the Agricultural Research Farm, BHU, Varanasi, India. Rice variety, Rajendra Kasturi was selected for this study and 22 days old seedlings were transplanted in main field with a spacing of $15 \times 20 \mathrm{~cm}^{2}$ in hills and all the agronomical practices viz. irrigation, fertilizer application and intercultural operations were followed as recommended for rice crop in this area to raise the crop in experimental sites.

A bulk plot of $100 \mathrm{~m}^{2}$ was prepared to study the population dynamics of rice earhead bug. The observations of pest population were recorded in this unprotected plot at 7 days interval (Standard weeks) from 7 days after transplanting (DAT) up to crop harvesting by the sweeping insect colleting nets of ten times across plot and the numbers of nymphs and adults' bug were counted. Weather data were recorded simultaneously from the meteorological observatory available at Agricultural Research Farm, Institute of Agricultural Sciences, BHU, Varanasi and correlated with the occurrence of the pest population. A correlation coefficient method was adopted to work out the relationship between the occurrence of the pest incidence and the weather parameters.

The experiment was laid out in a plot of $3 \times 3 \mathrm{~m}^{2}$ in randomized block design (RBD) with 3 replications. The experiments consist of nine treatments including control viz., fipronil $5 \%+$ buprofezin 20\% SC @ 62.5+250 g a.i./ha, indoxacarb 10\% + thiamethoxam 10\% WG @ 50+ 50 $\mathrm{g}$ a.i./ha, cypermethrin 10\% + indoxacarb 10\% SC @ 37.5+37.5 g a.i./ha, buprofezin 20\% SC @ $50 \mathrm{~g}$ a.i./ha, indoxacarb 14.5\% SC @ $125 \mathrm{~g}$ a.i./ha, thiamethoxam 25\% WG @ $25 \mathrm{~g}$ a.i./ha, chlorpyriphos 20\% EC @ $375 \mathrm{~g}$ a.i./ha, quinolphos 25\% EC @ $500 \mathrm{~g}$ a.i./ha and untreated control. All these insecticides were received from Gharda Chemicals Ltd., Thane, Maharashtra. The insecticidal solutions of desired concentrations as per each treatment were freshly prepared every time at the experimental site just before the start of spraying operation and sprays were done during the evening hours. A hand compression knapsack sprayer having cone nozzle was used for application of diluted treatments @ 500 1/ha. Two sprays were done during entire crop season when pest population/damage reaching the economic threshold level, first spray on just panicles emergence and second spray on grain filling stage of crop. The observations of rice earhead bugs (nymph and adult) were recorded by sweeping insect collecting nets five times across each treatment plots and the number of nymphs and adult bugs were counted one day prior to insecticidal application and 3rd, 7th, 10th and 14th days after application. The ANOVA of data recorded during the experiment was made for the insect pests under study and the calculated ' $\mathrm{F}$ ' was compared with tabulated ' $\mathrm{F}$ ' at $5 \%$ level of significance. The significance of mean difference between treatments was judged by $\mathrm{CD}$ at $5 \%$ level of significance.

\section{Results and Discussion}

The incidence of Leptocorsia acuta on rice was recorded as number of insects (adults and nymphs) per 10 sweep nets. Insect population was observed during 36th standard week when the crop is in tillering stage as 1 nos./10 sweep nets due to migration of insect from neighbouring 
field. However, these insects were observed to feed on weeds as collateral host (Dutta and Roy 2018). The population gradually increased on 38th standard week as 4 nos./10 sweep nets. Later, the population suddenly increased with 9 nos./10 sweep nets when the panicle emerged and gradually reached to 17 nos./10 sweep nets during 44th standard week. Thereafter, the population started to decline from 45th standard week with 7 nos./10 sweep nets and reached 1 nos./10 sweep nets on 47th standard week (Fig. 1). The pest was observed on the crop from tillering stage to harvest of crop. These results were in accordance with earlier findings made by Girish et al. (2012), that the pest appeared during reproductive stage of crop, but on the other hand Parwez et al. (2012) reported that the activity of pest started from 15th week of age of crop and remained infested throughout the crop period. Kalita et al. (2015) reported that in the first week of November the crop attained milking grains, then the pest population reached its peak.

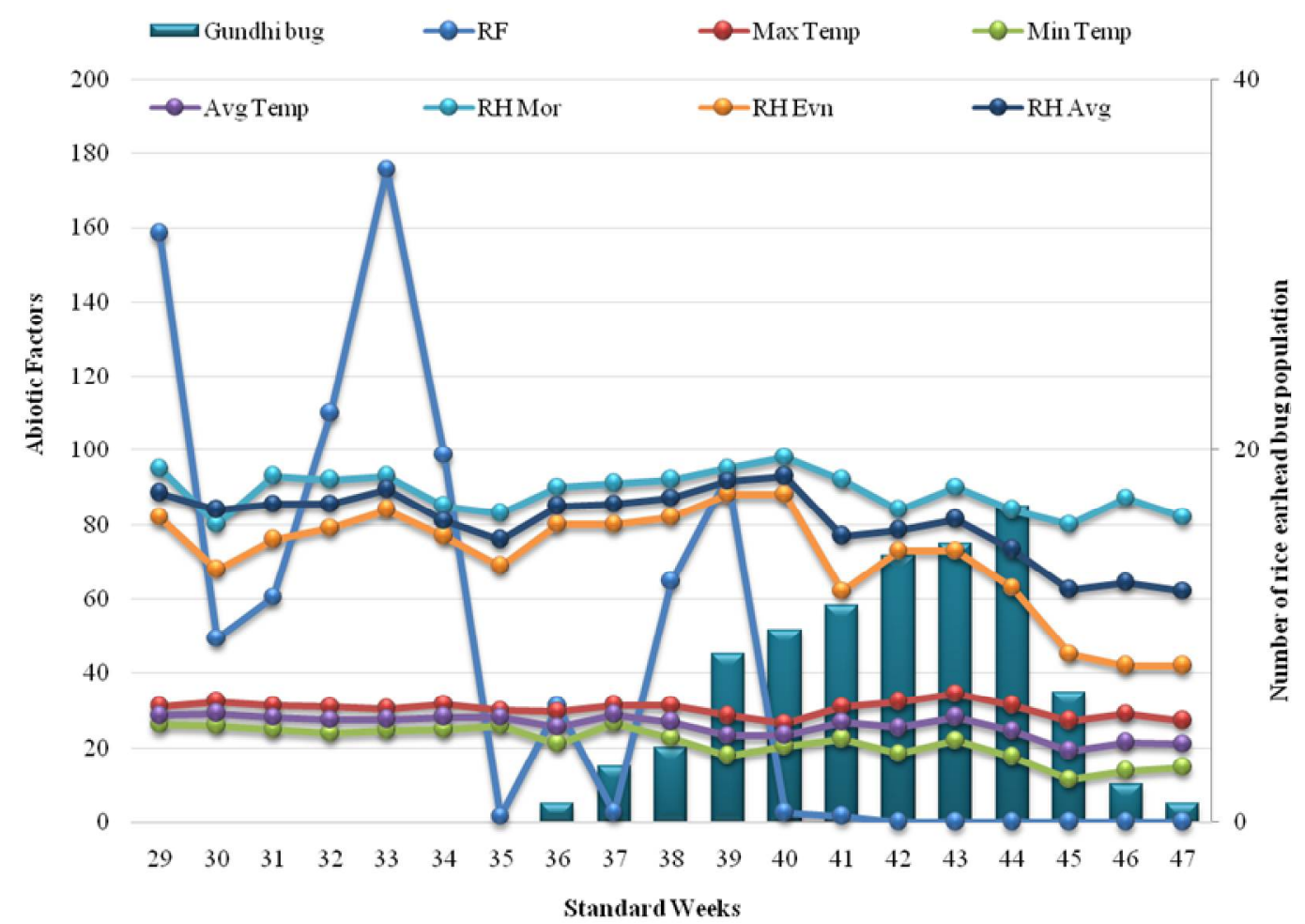

Fig. 1. Influence of environmental factors on the population dynamics of rice earhead bug.

The correlation analysis (Table 1) revealed that rice earhed bug showed a significant negative correlation with rainfall $(\mathrm{r}=-0.497)$ and a non-significant negative correlation with minimum temperature $(r=-0.397)$, average temperature $(r=-0.255)$, evening $\mathrm{RH}(\mathrm{r}=-0.040)$ and average RH $(r=-0.086)$. Further, a positive non-significant correlation was observed with maximum temperature $(r=0.152)$ and morning $\mathrm{RH}(\mathrm{r}=-0.018)$. The rice earhead bug showed a negative significant correlation with rainfall while the remaining weather parameters like evening relative humidity, average relative humidity, minimum and average temperature are negative and nonsignificantly correlated. A positive non-significant correlation was obtained with maximum temperature and morning RH. These results were in close conformity with the results obtaine3d by 
Roshan and Raju (2017) who reported a negative correlation of weather factors with pest population. Whereas Kalita et al. (2015) reported a positive non-significant correlation with maximum temperature.

Table 1. Correlation coefficient (r) of rice earhead bug population on rice with prevailing weather parameters during Kharif 2016.

\begin{tabular}{|c|c|c|c|c|c|c|c|}
\hline \multirow{3}{*}{$\begin{array}{l}\text { Insect } \\
\text { pests }\end{array}$} & \multicolumn{7}{|c|}{ Weather parameter } \\
\hline & \multirow{2}{*}{$\begin{array}{c}\text { Rainfall } \\
(\mathrm{mm})\end{array}$} & \multicolumn{3}{|c|}{ Relative humidity (\%) } & \multicolumn{3}{|c|}{ Temperature $\left({ }^{\circ} \mathrm{C}\right)$} \\
\hline & & Morning & Evening & Average & Maximum & Minimum & Average \\
\hline $\begin{array}{l}\text { Rice earhead } \\
\text { bug }\end{array}$ & $-0.497^{*}$ & 0.018 & -0.040 & -0.086 & 0.152 & -0.397 & -0.255 \\
\hline
\end{tabular}

*Correlation is significant at the 0.05 level.

Initially just before panicle formation stage of crop, the bugs migrated from neighbouring areas where they were feeding on weed that acted as collateral host and start multiplication. Prior to imposition of treatments during 1st spaying the population of rice earhead bug though varied from 3.48 - 4.74 nos./5 sweep nets but not varied significantly among the treatments (Table 2). The mean rice earhead bug population was the lowest in fipronil 5\% + buprofezin 20\% SC treated plots recording 2.05 nos. $/ 5$ sweep nets on 3rd day after first spray, followed by indoxacarb $10 \%+$ thiamethoxam 10\% WG 2.44 nos./5 sweep nets. Thiamethoxam 25 WG and buprofezin $25 \%$ SC alone with an average number of insects of 2.90 and 3.08 nos./5 hills, respectively which were found at par with each other. The same efficacy was maintained at 7 DAS also, the average number of rice earhead bug population was 1.17 nos. $/ 5$ hills in fipronil 5\% + buprofezin 20\% SC treated plots, followed by indoxacarb 10\% + thiamethoxam 10\% WG and thiamethoxam $25 \mathrm{WG}$ alone with an average number of insects of 1.51 and 1.86 nos./5 hills. Among insecticidal treatments, the highest population of rice earhead bug was recorded in chlorpyriphos treated plots as 3.73/5 hills and in untreated control was 6.43 nos./5 hills. The rice earhead bug population counted on 10th and 14th DAS was also significantly lower in fipronil 5\% + buprofezin 20\% SC treated plots (2.10 and 3.08 nos./5 hills, respectively), followed by indoxacarb $10 \%+$ thiamethoxam 10\% WG (2.49 and 3.45 nos./5 hills, respectively). Whereas, the plots treated with chlorpyriphos $20 \%$ EC highest insect population of 5.16 and 6.28 insects nos./5 sweep, while the population in control reached 7.57 and 9.57 nos./5 hills, respectively (Table 2).

The population of insect suddenly increased when the panicles fully emerged and attained it milking stage. During the second spray, rice earhead bug population ranged from 8.53 to 13.18 nos./5 sweep nets prior to imposition of treatments (Table 2). However, 3rd day after imposing the treatment, fipronil 5\% + buprofezin 20\% SC treated plots recorded a lowest number of rice earhead bug 4.21 insects nos./5 sweep nets and differed significantly from the average number of insects observed in rest of the insecticide treated plots, followed by indoxacarb $10 \%+$ thiamethoxam 10\% WG (5.11 nos./5 hills), thiamethoxam 25 WG (5.88 nos./5 hills) and buprofezin $25 \mathrm{SC}$ (6.63 nos./5 hills) and higher number of insect counts were observed in chlorpyriphos 20EC (9.98 nos./5 hills) and untreated control (13.18 nos./ 5 hills). Same trend was followed after 7th, 10th and 14th DAS. The data of overall mean revealed that, fipronil $5 \%+$ buprofezin $20 \%$ SC treated plots showed the lowest population 3.51 nos./5 hills, followed indoxacarb $10 \%$ + thiamethoxam $10 \%$ WG (4.25 nos./5 hills), thiamethoxam $25 \mathrm{WG}$ (5.29 nos. $/ 5$ hills) and buprofezin $25 \mathrm{SC}$ (6.10 nos./5 hills) were significantly different from each other. However, the highest population was recorded in chlorpyriphos treated plots 9.65 hills while rice earhead bug population in untreated control was 14.67 nos. $/ 5$ hills (Table 2). 


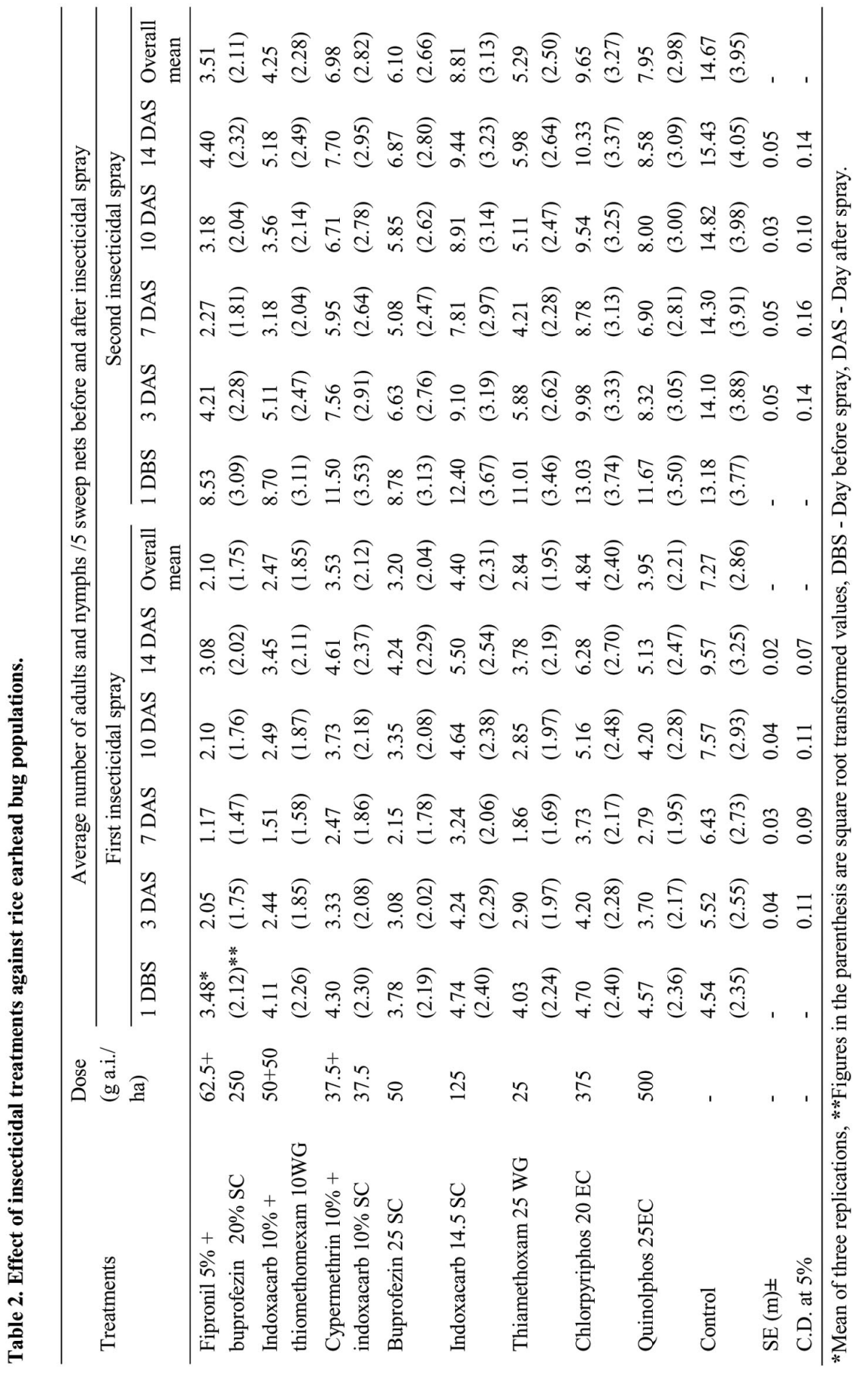


The data on overall field efficacy in both the sprays revealed that fipronil $5 \%+$ buprofezin $20 \%$ SC was found consistently most effective treatment followed by indoxacarb $10 \%+$ thiamethoxam 10\% WG, thiamethoxam 25\% WG and buprofezin 25\% SC treatments. Cypermethrin 10\% + indoxacarb 10\% SC and quinolphos 25\% EC were moderately effective, while indoxacarb $14.5 \% \mathrm{SC}$ and chlorpyriphos $20 \% \mathrm{EC}$ were less effective. The results of present investigation revealed that a combination of insecticide formulation, fipronil $5 \%+$ buprofezin $20 \%$ SC (phenyl pyrazole and chitin synthesis inhibitor) and indoxacarb 10\% + thiamethoxam $10 \%$ WG (contact and systemic mode of action) was found consistently most effective treatment. The present finding is in agreement with the reports of Roshan and Raju (2017) who confirmed that a combination insecticide acetamiprid + fipronil (different combinations) was most effective against rice earhead bug. Zainab and Singh (2016) also found that a combination of chlorpyrifos $35 \%$ + fipronil 3.5\% EC was most effective in reducing rice earhead bug population. While, Chaudhary and Raghuraman (2014) observed that combination of buprofezin 15\% + acephate 35\% WP showed different mode of action where insecticides were most effective against rice earhead bug. However, in sole insecticides thiamethoxam and buprofezin was also found to be effective against rice earhead bug and these results corroborated with Girish and Balikai (2015) who reported that sole treatment of thiamethoxam 25 WG @ $(0.3 \mathrm{~g} / \mathrm{l})$ was found to be superior treatment over rest of the treatments by recording the minimum earhead bug population, while Baruah et al. (2016) reported that the buprofezin was also effective in reducing rice earhead bug population.

From the present results, it may be concluded that the peak period of rice earhead bug population was in 44th standard week. The correlation studies with environmental factors revealed that rainfall showed a significant negative impact on the population of rice earhead bug. These findings could be helpful for proper forewarn and timely management of rice earhead. Fipronil 5\% + buprofezin 20\% SC (phenyl pyrazole and chitin synthesis inhibitor) and indoxacarb 10\% + thiamethoxam 10\% WG (contact and systemic mode of action) combination formulations rendered effective control than the sole insecticide treatments of buprofezin and thiamethoxam against rice earhead bug. This combination will not only enhance the choice of farmers in selecting the insecticides from different groups and different mode of action and can play an important role as an alternative to neonicotinoids and pyrethroids used by the farmers for the control of rice earhead bug but also significantly play a vital role in the insecticide resistance management.

\section{Acknowledgements}

The authors are grateful to M/s Gharda Chemicals Ltd., Thane, Maharashtra, India for sponsoring the studies and the Head, Department of Entomology and Agril. Zoology, Institute of Agricultural Sciences, Banaras Hindu University, Varanasi, India for providing facilities to conduct the experiments.

\section{References}

Anonymous 2017. Annual report 2016-17 by Department of Agriculture, Cooperation \& Farmers Welfare, Ministry of Agriculture \& Farmers Welfare Government of India. p. 3.

Banerjee PK and Chatterjee PB 1982. Pests of hill rice in West Bangal, India. International Rice Res. News Letter 7(4): 12-14.

Baruah M, Medhi AK and Dey PC 2016. Field evaluation of new insecticide molecules against certain major insect pests in rice ecosystem of Assam. Env. and Ecology 34(4B): 2217-2220.

Chaudhary S and Raghuraman M 2014. Impact of chitin synthesis inhibitor on brown planthopper (bph), Nilaparvata lugens (Stal.) and gundhi bug, Leptocorisa acuta (Thunberg) in rice. International Journal of Plant Protection 7(2): 369-372. 
Dutta S and Roy N 2018. Host preference and population dynamics of a major pest, Leptocorisa acuta (Thunb.), for their ecological management. Int. J. of Bio. Res. 3(2): 31-39.

Girish VP, Hegde M, Hanamaratti NG and Balikai RA 2012. Population dynamics of leafhopper, grasshopper, horned caterpillar and ear head bugs under different planting methods of rice ecosystem. J. Expt. Zool. India 15(2): 451-454.

Girish VP and Balikai RA 2015. Efficacy of botanicals, biopesticides and insecticide molecules against ear head bug, Leptocorisa acuta (thunberg) in paddy and their effect on yield. J. Expt. Zool. India 18(2): 943-946.

Hashmi AA, Naemullah M and Arshad M 1983. Economic threshold levels of important insect pests of crops. Prog. Farming 3: 24-30.

Israel P and Rao YS 1961. Incidences of gundhi bug and steps for control. Protocol Rice Research Works Management. CRRI, Cuttack. pp. 297-299.

Kalita H, Avasthe RK and Ramesh K 2015. Effect of weather parameters on population buildup of different insect pests of rice and their natural enemies. Indian Journal of Hill Farming 28(1): 69-72.

Kalode MB 2005. Insect pest of rice and their management in rice in Indian perspective. SD Sharma and BC Nayak (Ed.). Today and Tomorrow Printers and Publishers, India. pp. 819-854.

Nadaf A, Mathure S and Jawali N 2016. Introduction in scented rice (Oryza sativa L.) cutivars of India: A prospective on quality and diversity. Springer, New Delhi. pp. 1-6.

Parwez A, Singh SK, Shankar T, Singh PK and Singh SS 2012. Leptocorisa vericornis - weather relationship studies in Boro rice. Journal of Interacademicia 16(2): 274-277.

Roshan DR and Raju SVS 2017. Seasonal abundance of Leptocorsia acuta (Thunberg) and its management with novel insecticides. Trends of Biosciences 10(19): 3439-3442.

Sharma KR, Raju SVS, Roshan, DR and Jaiswal DK 2018. Effect of abiotic factors on yellow stem borer, Scirpophaga incertulas (Walker) and rice leaf folder, Cnaphalocrocis medinalis (guenee) population, J. Expt. Zool. India 21(1): 233-236.

Verma SK, Pathal PK, Singh BN and Lal MN 1979. Leaf folder and rice gundhi bug break in tarai and hill region of Uttar Pradesh, India. International Rice Research Notes 4: 20.

Zainab S and Singh RN 2016. Bio-efficacy of combination of insecticdes against brown plant hooper, Nilaparvata lugens (Stal) and rice gundhi bug, Leptocorisa varicornis (Fabr) in rice. Journal of Agricultural and Statistical Sciences 12(Suppl. 1): 29-33. 